

 \\ UNIVERSITEIT \\ GENT
}

biblio.ugent.be

The UGent Institutional Repository is the electronic archiving and dissemination platform for all UGent research publications. Ghent University has implemented a mandate stipulating that all academic publications of UGent researchers should be deposited and archived in this repository. Except for items where current copyright restrictions apply, these papers are available in Open Access.

This item is the archived peer-reviewed author-version of: A multivariate approach to predict the volumetric and gravimetric feeding behavior of a low feed rate feeder based on raw material properties

Authors: Bostijn N., Dhondt J., Ryckaert A., Szabo E., Dhondt W., Van Snick B., Vanhoorne V., Vervaet C., De Beer T.

In: International Journal of Pharmaceutics, 557: 342-353

To refer to or to cite this work, please use the citation to the published version:

Bostijn N., Dhondt J., Ryckaert A., Szabo E., Dhondt W., Van Snick B., Vanhoorne V., Vervaet C., De Beer T. (2019) A multivariate approach to predict the volumetric and gravimetric feeding behavior of a low feed rate feeder based on raw material properties

International Journal of Pharmaceutics, 557: 342-353

DOI: 10.1016/j.ijpharm.2018.12.066 


\section{A multivariate approach to predict the volumetric and gravimetric feeding behavior of a low feed rate feeder based on raw material properties}

N. Bostijn ${ }^{a}$, J. Dhondt a , A. Ryckaert ${ }^{a}$, E. Szabó ${ }^{a}$, W. Dhondt ${ }^{b}$, B. Van Snick ${ }^{c}, d$, V. Vanhoorne ${ }^{\text {c, }}$ C. Vervaet ${ }^{c}$, T. De Beer ${ }^{\mathrm{a},{ }^{*}}$

a Laboratory of Pharmaceutical Process Analytical Technology, Department of Pharmaceutical Analysis, Ghent University, Ottergemsesteenweg 460, 9000 Ghent, Belgium

b Global Technical Operations, Pharmaceutical Mfg (PM) Platform, Turnhoutseweg 30, 2340 Beerse, Belgium

c Laboratory of Pharmaceutical Technology, Department of Pharmaceutics, Ghent University, Ottergemsesteenweg 460, 9000 Ghent, Belgium

d Oral Solid Dosage, Drug Product Development, Pharmaceutical Development and Manufacturing Sciences, Pharmaceutical Research and Development, Division of Janssen Pharmaceutica, Johnson \& Johnson, Turnhoutseweg 30, 2340 Beerse, Belgium

${ }^{*}$ Corresponding author: Thomas De Beer

Ghent University

Laboratory of Pharmaceutical Process Analytical Technology

Ottergemsesteenweg 460

9000 Ghent (Belgium)

Tel. +3292648097

Fax +32 92228236

E-mail: Thomas.DeBeer@UGent.be 


\section{Abstract}

2 In this study, the volumetric and gravimetric feeding behavior of 15 pharmaceutical

3 powders on a low feed rate feeder was correlated with their material properties through a

4 multivariate approach. The powders under investigation differ substantially in terms of

5 material properties, making the selected powders representative for powders typically

6 used in pharmaceutical manufacturing. The material properties were described by 25

7 material property descriptors, obtained from a rational selection of critical characterization

8 techniques that provided maximal information with minimal characterization effort. From

9 volumetric feeding experiments (i.e., powder feed rate not controlled), the maximum

10 feeding capacity (maximum feed factor $\left(F F_{\max }\right)$ ) and optimal hopper fill level at which the

11 feeder should be refilled during gravimetric feeding (feed factor decay (FF $\left.F_{\text {decay }}\right)$ ) were

12 obtained. During gravimetric feeding experiments (i.e., powder feed rate controlled), the

13 variability on the feed rate (relative standard deviation (RSD)) and the difference between

14 the setpoint and mean feed rate (relative error $(\mathrm{RE})$ ) were determined. Partial least

15 squares (PLS) regression was applied to correlate the volumetric and gravimetric feeding

16 responses $(\mathrm{Y})$ with the material property descriptors $(\mathrm{X})$. The predictive ability of the

17 developed PLS models was assessed by predicting the feeding responses of two new

18 powders (i.e., validation set). Overall, the volumetric feeding responses (FFmax and

$19 \mathrm{FF}_{\text {decay }}$ ) were predicted better than the gravimetric feeding responses (RSD and RE),

20 since in gravimetric mode the impact of material properties on the feeding behavior is

21 reduced due to the control system of the feeder. Especially RE was weakly correlated with

22 material properties as RE of most powders varied around zero with only a small numerical

23 variation. Interestingly, this confirms that the control system is working properly and that 
24 the feeder is capable of feeding different powders accurately at low feed rates. The

25 developed models allowed to predict the feeding behavior of new powders based on their

26 material properties. Consequently the number of feeding experiments during process

27 development can be greatly reduced, thereby leading to a more efficient and faster

28 development of new drug products.

29 Keywords

30 Continuous manufacturing, Twin screw feeding, Material properties, Material

31 characterization, Multivariate data analysis.

\section{Abbreviations}

$33200 \mathrm{M}$, lactose monohydrate; API, active pharmaceutical ingredient; API M, API

34 micronized; API SD, spray dried API; AV, air velocity; CL, crospovidone; DCP, dibasic

35 calcium phosphate; FF decay, feed factor decay; FFmax, maximum feed factor; HD90,

36 silicified microcrystalline cellulose; LIW, loss-in-weight; MgSt, magnesium stearate; P D,

37 paracetamol dense; P M, paracetamol micronized; $\mathrm{P} P$, paracetamol powder; PCA,

38 principal component analysis; PH105, microcrystalline cellulose; PLS, partial least

39 squares; PLSC, partial least squares component; $\mathrm{Q}^{2}$, predictive ability; $\mathrm{R}^{2}$, goodness of

40 fit; RE, relative error; rpm, revolutions per minute; RSD, relative standard deviation;

41 S1500, pre-gelatinized starch; SD, standard deviation; UV, unit variance. 


\section{INTRODUCTION}

46 In a continuous manufacturing line, feeding of the raw materials is generally the first unit

47 operation and is crucial towards the success of the complete manufacturing process

48 (Simonaho et al., 2016). Inaccurate and inconsistent feeding of raw materials can lead to

49 an impaired product quality (e.g., incorrect active pharmaceutical ingredient (API)

50 concentration), since the composition of the final product is determined by the feed rate

51 of the individual raw materials (Ervasti et al., 2015). Loss-in-weight (LIW) feeders consist

52 of a feeding device, weighing platform and control system (Engisch and Muzzio, 2015a).

53 The feeding device is placed on the weighing platform, which measures the weight of the

54 feeding device together with the powder in the feeding device. A LIW feeder can work in

55 two modes, i.e., gravimetric or volumetric. In gravimetric mode, the control system

56 acquires the mass of the feeding device and its content from the weighing platform as a

57 function of time during feeding. The actual feed rate is calculated from the difference in

58 mass, measured by the weighing platform, divided by the difference in time between

59 consecutive measurements. The control system minimizes the difference between the

60 actual feed rate and the feed rate setpoint by adjusting the dispensing rate (e.g., screw

61 speed) of the feeding device (Coperion K-Tron, 2012). Thus in gravimetric mode the

62 powder feed rate is controlled to account for sources of variability, such as variations in

63 material density when the powder level in the hopper changes during feeding (Van Snick

64 et al., 2017a). The volumetric mode is characterized by the displacement of a constant

65 material volume per unit of time instead of a constant mass per unit of time as in

66 gravimetric mode. The screw speed of the feeding device is kept constant during

67 volumetric feeding, implying that the powder feed rate is not controlled (Blackshields and 
68 Crean, 2017). For pharmaceutical applications, where the feeding accuracy of the

69 individual raw materials is critical and the density of the processed powders can vary, the

70 gravimetric feeding mode is preferred. A LIW feeder operating in gravimetric mode will

71 switch to volumetric mode during hopper refill, because the weight loss cannot be

72 accurately measured when material is entering and leaving the feeder at the same time

73 (Engisch and Muzzio, 2015b).

74 APls and excipients used in pharmaceutical formulations differ a lot in terms of material 75 properties (e.g., density, particle size, flowability) and these differences can be reflected 76 in the process behavior (El Hagrasy et al., 2013; Engisch and Muzzio, 2015a; Fonteyne 77 et al., 2015; Herting and Kleinebudde, 2007). Therefore, an approach that captures the 78 variability in material properties of different powders and subsequently correlates this with

79 process behavior at different unit operations can facilitate product and process 80 development. The first step is to establish a database containing all the appropriate 81 material properties from a wide selection of representative powders. Such an extensive 82 raw material property database was recently developed by Van Snick et al. (Van Snick et 83 al., 2018a), in which more than 50 pharmaceutical powders were characterized in detail 84 using a wide variety of techniques resulting in more than 100 material property descriptors.

85 The included raw materials ranged from excipients used during direct compression, roller 86 compaction and wet granulation to different types of APIs. Subsequently, principal 87 component analysis (PCA) was used to reveal the correlations between the included raw 88 materials and their material properties.

89 In a next step, the material properties can be linked via multivariate models with the 90 process behavior at different unit operations of a continuous manufacturing line (e.g., 
91 feeders, blenders) (Clayton, 2015). Research has already been successfully conducted

92 using this approach for granulation and tableting processes (Fonteyne et al., 2014;

93 Garcia-Munoz, 2014; Haware et al., 2009a, 2009b; Thoorens et al., 2015; Van Snick et

94 al., 2018b; Willecke et al., 2017). Once a predictive platform is developed for a unit

95 operation, the characterization of a small amount of powder is sufficient to predict the

96 behavior of that material at the specific unit operation. This significantly reduces the

97 otherwise numerous experiments to a handful of confirmatory experiments to verify the

98 predicted process behavior. Such an approach is especially useful during the early stages

99 of drug product development, when only a limited amount of API is available. By being

100 able to predict the process and product performance, the material consumption and

101 development time can be greatly reduced, leading to a more efficient and faster 102 development of new drug products (Wang et al., 2017). In addition, a surrogate powder

103 with similar material properties as the API can be selected and used during experiments

104 instead of the original API, thereby further limiting the API consumption (Boukouvala and

105 lerapetritou, 2013).

106 Wang et al. developed a model for predicting the gravimetric feeding behavior of a K-Tron

107 KT20 twin screw LIW feeder based on the material flow properties of seven raw materials

108 using PLS regression (Wang et al., 2017). Three feeder screws, differing in feeding

109 capacity and self-cleaning ability, were tested and the gravimetric feeding performance

110 was described by the consistency of the feed rate (RSD) and the difference between the

111 mean and target feed rate (RE). They concluded that feeding performance was affected

112 by the material flow properties and that the predicted feeding responses were in good

113 agreement with the experimental results. In addition, a strong correlation between the 
114 initial feed factor and the material flow properties was observed. This initial feed factor

115 was determined during the volumetric calibration and refers to the maximum feeding 116 capacity for a given screw and material (Engisch and Muzzio, 2012). Van Snick et al.

117 investigated the importance of volumetric feeding experiments on a GEA compact feeder 118 and introduced the feed factor profile, in which the feed factor was plotted as a function of

119 hopper fill level (Van Snick et al., 2017a). From these feed factor profiles, the maximum

120 feeding capacity was derived and a suitable refill strategy was selected for each tested

121 material. The maximum feeding capacity correlated with bulk density and partly with flow

122 properties, whereas highly compressible powders with a low density exhibited a feed

123 factor decrease at higher hopper fill levels.

124 The feeders used by Wang et al. and Van Snick et al. are high feed rate feeders (feed 125 rate $>1 \mathrm{~kg} / \mathrm{h}$ ), while the correlation of material properties with the feeding behavior of low 126 feed rate feeders (feed rate $<1 \mathrm{~kg} / \mathrm{h}$ ) is not yet described in literature. Developing such 127 predictive models is especially relevant for low feed rate feeders as these feeders are 128 generally used for low-dosed raw materials (e.g., APIs). In addition, the growing interest 129 within the pharmaceutical industry for high-potency active pharmaceutical ingredients 130 further encourages the need of a predictive platform for these types of feeders (Besenhard 131 et al., 2016).

132 This study is an application of the raw material property database developed by Van Snick 133 et al (Van Snick et al., 2018a). While they developed a PCA model and identified the 134 correlated and relevant material property descriptors, the current study aims at linking 135 these relevant material property descriptors with the volumetric and gravimetric feeding 136 behavior of a low feed rate feeder. The 15 pharmaceutical powders included in this study 
137 were selected from the powders used by Van Snick et al., making the selection

138 representative for powders commonly used in pharmaceutical manufacturing. The

139 material properties of the powders were determined and described by 25 material property

140 descriptors obtained from seven characterization techniques. These characterization

141 techniques were identified by Van Snick et al. as the rational selection of critical

142 characterization techniques that provide maximal information with minimal

143 characterization effort. The volumetric feeding experiments were used to construct feed

144 factor profiles, from which the maximum feed factor and feed factor decay were obtained.

145 During gravimetric feeding experiments, the variability on the feed rate (RSD) and the

146 difference between the setpoint and mean feed rate (RE) were determined. Next, the

147 material property descriptors were correlated with both the volumetric and gravimetric

148 feeding responses via PLS regression. The predictive performance of the models was

149 assessed by predicting the feeding responses of two validation powders.

150 2. MATERIALS AND METHODS

\section{2.1. Materials}

152 The raw materials included in this study were selected from the raw material database

153 described by Van Snick et al (Van Snick et al., 2018a). Furthermore, additional APIs were

154 included as these APIs will be used in an application where the studied feeder will be

155 implemented in a continuous manufacturing line for pharmaceutical semi-solid and liquid

156 formulations (Bostijn et al., 2018). The following 15 raw materials were used in this study:

157 lactose monohydrate (200M) (Lactose 200M, DFE, Goch, Germany), microcrystalline

158 cellulose (PH105) (Avicel PH-105, FMC, Philadelphia, PA, USA), dibasic calcium 
159 phosphate (DCP) (Emcompress AN, JRS, Rosenberg, Germany), silicified 160 microcrystalline cellulose (HD90) (Prosolv HD90, JRS, Rosenberg, Germany), 161 crospovidone (CL) (Kollidon CL, BASF, Ludwigshafen, Germany), pre-gelatinized starch 162 (S1500) (starch 1500, Colorcon, Dartford, UK), magnesium stearate (MgSt) (Ligamed MF163 2-V, Peter Greven, Bad Münstereifel, Germany), spray dried API (API SD) (Janssen, 164 Beerse, Belgium), paracetamol dense (P D) (Mallinckrodt, Dublin, Ireland), paracetamol 165 powder (P P) (Mallinckrodt, Dublin, Ireland), paracetamol micronized (P M) (Mallinckrodt, 166 Dublin, Ireland), API 1 (Janssen, Beerse, Belgium), API 2 (Janssen, Beerse, Belgium), 167 API 3 (Janssen, Beerse, Belgium) and API micronized (API M) (Janssen, Beerse, 168 Belgium). In total, seven excipients and eight APIs were investigated. The powders were 169 divided in a calibration and validation set (section 2.2.4.). S1500 (excipient) and API 3 170 were selected as powders for the validation set since both exhibited a different feeding 171 behavior and the values of their material property descriptors fell within the numerical 172 ranges of the calibration set. The details of some APls are not provided due to 173 confidentiality reasons.

\section{2.2. Methods}

175 2.2.1. Equipment

$176 \quad$ 2.2.1.1. K-Tron MT12 LIW feeder

177 The feeder used in this study was a K-Tron MT12 twin screw co-rotating LIW feeder

178 (Coperion K-Tron, Niederlenz, Switzerland) (figure 1). The motor and weighing platform

179 were enclosed within the feeder base and the feeding screws were connected to the motor 180 via a gearbox (gear ratio of $1: 1$ ). A drive command of $100 \%$ corresponded to a maximum 
181 screw speed of $60 \mathrm{rpm}$. Concave coarse screws were used with a diameter of $12 \mathrm{~mm}$ and

182 a pitch distance of $5.75 \mathrm{~mm}$. The hopper, having a volume of $1 \mathrm{~L}$, was equipped with an

183 agitator. At the bottom part of the agitator, three blades consistently filled the flights of the

184 screws. The vertical rods of the agitator promoted the material flow in the hopper and 185 prevented material from bridging on the side walls. The feeder was not equipped with a 186 refill system and the hopper was not manually refilled during the experiments.

187 Operating the feeder was done via the K-Tron control module. All feeder data (screw 188 speed, net weight, ...) was logged every $1 \mathrm{~s}$ during the experiments. Before the start of 189 an experiment, the empty feeder was tared. Next, the hopper was filled and the screws 190 were primed with powder. After priming, the hopper was filled up to $1 \mathrm{~L}$ and the 191 corresponding weight was recorded and considered as maximal (i.e., 100\% hopper fill 192 level).

\section{$193 \quad$ 2.2.1.2. Catch scale}

194 A catch scale (Coperion K-Tron, Niederlenz, Switzerland) was placed under the outlet of 195 the feeder to record the powder feed rate every $1 \mathrm{~s}$ and the fed powder was collected in 196 a beaker (figure 1). The catch scale was used to obtain the raw feed rate, because the

197 feed rate calculated by the feeder is already pre-treated according to an algorithm from

198 the feeder manufacturer. If the feed rate of the feeder would be used, it would be difficult

199 to compare feeder performance between feeders of different manufacturers.

200 2.2.2. Feeder characterization methodology

$201 \quad$ 2.2.2.1. Volumetric feeding 
202 After performing the start-up feeder protocol (i.e., taring, priming of the screws and

203 determining the maximum weight in the hopper), each powder was volumetrically fed at

204 three different screw speeds: 10,50 and $90 \%$ of the maximum screw speed (60 rpm),

205 corresponding to screw speeds of 6,30 and $54 \mathrm{rpm}$, respectively. These screw speeds

206 cover the screw speed range that is generally used during manufacturing. Because the

207 volumetric mode was selected, the control system did not control the feed rate by

208 correcting the screw speed and thus the screw speed remained constant during each

209 experiment. All volumetric experiments were stopped when the hopper ran empty.

210 The aim of the volumetric experiments was to obtain a feed factor profile of each powder

211 at each tested screw speed. In a feed factor profile, the feed factor is plotted as a function

212 of the hopper fill level (\%) (figure 2). The feed factor (g/revolution) (eq. 1) is the powder

213 mass dispensed per screw revolution and was calculated from the actual feed rate $(\mathrm{kg} / \mathrm{h})$,

214 obtained from the catch scale, and the screw speed (revolutions/s) using the following

215 equation:

$$
\text { feed factor }\left(\frac{g}{\text { revolution }}\right)=\frac{\text { feed rate }\left(\frac{\mathrm{kg}}{h}\right)}{\text { screw speed }\left(\frac{\text { revolutions }}{s}\right) \times 3.6} \text { (1) }
$$

217 with 3.6 the conversion factor to convert $\mathrm{kg} / \mathrm{h}$ into $\mathrm{g} / \mathrm{s}$. The feed rate $(\mathrm{kg} / \mathrm{h})$ (eq. 2) was

218 calculated using the difference in weight $\left(\Delta \mathrm{W}_{\text {catch scale }}\right)(\mathrm{g})$ measured by the catch scale

219 divided by the difference in time ( $1 \mathrm{~s})$ between consecutive catch scale measurements

$220(\Delta \mathrm{t})(\mathrm{s}):$ 
222 with 3.6 the conversion factor to convert $\mathrm{g} / \mathrm{s}$ into $\mathrm{kg} / \mathrm{h}$. In order to compare feed factor

223 profiles of powders with a different density (i.e., different net weight of a full hopper), the

224 net weight of the hopper $(\mathrm{kg})$ was normalized for the maximum powder mass in the hopper

225 (kg) for a specific powder and expressed as the hopper fill level \% (eq. 3):

$$
\text { fill level } \%=\frac{\text { net weight }(\mathrm{kg})}{\text { maximum net weight }(\mathrm{kg})} \times 100
$$

227 Once a feed factor profile was obtained for a specific material at a given screw speed, the 228 maximum feed factor ( $\left.F F_{\max }\right)$ and feed factor decay (FF decay) were extracted (figure 2).

229 Prior to the determination of these volumetric feeding responses, the disturbance of a

230 beaker replacement was removed from the feed factor profile. The remaining data was

231 averaged (i.e., moving average of $20 \mathrm{~s}$ ) to enhance the interpretability of the feed factor

232 profiles. FF $_{\max }$ expresses the maximum feeding capacity of a feeder for a specific material

233 and can be used to calculate the maximum achievable feed rate in gravimetric mode.

$234 \mathrm{FF}_{\max }$ was determined from the feed factor profile as the highest observed feed factor at 235 each tested screw speed (figure 2).

236 In general, the feed factor is highest (i.e., $\mathrm{FF}_{\max }$ ) at $100 \%$ hopper fill level and gradually 237 decreases during feeding (i.e., decreasing hopper fill level) (figure 2). This decrease in 238 feed factor was described by $\mathrm{FF}_{\text {decay }}$, defined as the \% hopper fill level where the feed 239 factor drops to $90 \%$ of $F F_{\max }$. $F F_{\text {decay }}$ can help to define the hopper refill strategy during 240 gravimetric feeding, thereby reducing the variability induced by a hopper refill. Since the

241 feeder is operating in volumetric mode during a hopper refill, the feeder is not able to 242 compensate for the increasing density of the powder inside the hopper (i.e., increase in 243 feed factor) when incoming material compresses this powder. In addition, the feeder 
244 screw speed can suddenly change when the feeder returns to gravimetric mode after a

245 refill because of the changed density (Nowak, 2016). Therefore, selecting the optimal

246 hopper fill level at which the hopper should be refilled is essential to minimize the deviation

247 from the feed rate setpoint during and after a refill. The threshold of $90 \%$ of $\mathrm{FF}_{\max }$ was

248 selected as a lower \% will result in a larger difference in feed factor before and after a refill

249 and a higher \% will require the feeder to be refilled too frequently (Engisch and Muzzio,

250 2015b). The impact of screw speed on $\mathrm{FF}_{\max }$ and $\mathrm{FF}_{\text {decay }}$ was also investigated, since

251 these volumetric feeding responses were determined at three different screw speeds.

252 Hence, $\mathrm{FF}_{\max }$ and $\mathrm{FF}_{\text {decay }}$ at a screw speed of 6, 30 and $54 \mathrm{rpm}$ were obtained for each

253 powder (from now on referred to as $\mathrm{FF}_{\max } 6,30$ and $54 \mathrm{rpm}$ and $\mathrm{FF}_{\text {decay }} 6,30$ and $54 \mathrm{rpm}$ ).

\section{$254 \quad$ 2.2.2.2. Gravimetric feeding}

255 After performing the start-up feeder protocol (i.e., taring, priming of the screws and

256 determining the maximum weight in the hopper), the feeder was calibrated in volumetric

257 mode to determine the feed rate at the maximum screw speed $(60 \mathrm{rpm})$. Next, the hopper

258 was refilled to reach a fill level of $100 \%$ after the calibration. For the gravimetric 259 experiments (i.e., controlled feed rate), the powders were tested at a low and high feed

260 rate setpoint $(0.1$ and $0.55 \mathrm{~kg} / \mathrm{h})$ and each experiment was stopped after 20 minutes.

261 These feed rate setpoints were selected based on another study where the gravimetric

262 feeding behavior of a K-Tron KT20 and GEA compact feeder was determined (Van Snick

263 et al., 2017b). By selecting the same feed rate setpoints, the gravimetric feeding 264 performance between the different feeders can be directly compared. 
265 The standard deviation (SD) (kg/h) (eq. 4), relative standard deviation (RSD) (\%) (eq. 5)

266 and relative error (RE) (\%) (eq. 6) (i.e., relative difference between the mean and target

267 feed rate) were calculated from the feed rate $(\mathrm{kg} / \mathrm{h})$ measured by the catch scale (figure

268 3):

$$
\begin{gathered}
S D=\sqrt{\frac{\sum_{1}^{k}(\text { feed rate- } \overline{\text { feed rate }})^{2}}{k}} \\
R S D=\frac{S D}{\text { feed rate }} \times 100 \\
R E=\frac{\mid \text { feed rate }- \text { target feed rate } \mid}{\text { target feed rate }} \times 100
\end{gathered}
$$

272 with feed rate $(\mathrm{kg} / \mathrm{h})$ the mean feed rate and $\mathrm{k}$ the number of time points. RSD and RE

273 were used to express the variability on the feed rate and deviation of the mean feed rate

274 from the setpoint, respectively. Data outside the \pm 3 SD interval were excluded together

275 with $7 \mathrm{~s}$ of data before and after an outlier. After filtering, SD, RSD and RE were

276 recalculated. This pre-treatment was necessary to remove disturbances that were not

277 related to the feeding but rather to the sensitivity of the catch scale (e.g., opening and 278 closing of a door). In total, four gravimetric feeding responses were obtained for each

279 powder: RSD and RE at the feed rate setpoints of 0.1 and $0.55 \mathrm{~kg} / \mathrm{h}$ (from now on referred 280 to as RSD 0.1 and $0.55 \mathrm{~kg} / \mathrm{h}$ and RE 0.1 and $0.55 \mathrm{~kg} / \mathrm{h}$ ).

\section{2.2.3. Powder characterization techniques}

282 An overview of the used characterization techniques, corresponding material property 283 descriptors and abbreviations is provided in table 1.

\section{$284 \quad$ 2.2.3.1. Laser diffraction}


285 Laser diffraction (Mastersizer S, Malvern Instruments, Worcestershire, UK) was used to 286 measure the particle size of the powders. All measurements were conducted with a MS64

287 dry powder feeder unit using a $300 \mathrm{RF}$ lens at a feed rate of $3.0 \mathrm{G}$. Each measurement 288 was carried out in triplicate. The particle size was reported as a volume equivalent sphere 289 diameter. The $50 \%$ cumulative undersize of the volumetric distribution was described as 290 dv50 ( $\mu \mathrm{m})$. Particle size analysis was done via the Mastersizer S software.

\section{$291 \quad$ 2.2.3.2. Density and porosity}

292 Bulk $\left(\rho_{b}\right)$ and tapped $\left(\rho_{t}\right)$ density $(\mathrm{g} / \mathrm{ml})$ were measured in triplicate with a graduated 293 cylinder mounted on an automatic tapping device (PT TD200, PharmaTest, Hainburg,

294 Germany). A known mass (M) (g) of powder was poured into a graduated cylinder and the 295 initial volume $\left(\mathrm{V}_{0}\right)(\mathrm{ml})$ was determined. After 1250 taps the volume $\left(\mathrm{V}_{1250}\right)(\mathrm{ml})$ was also 296 measured. The bulk density was calculated as $\mathrm{M} / \mathrm{V}_{0}$ and the tapped density as $\mathrm{M} / \mathrm{V}_{1250 .}$

297 Furthermore, the Hausner ratio $(\mathrm{HR})$ was calculated as $\mathrm{V}_{0} / \mathrm{V}_{1250}$ and the Carr index $(\mathrm{Cl})$ 298 as $\left(\mathrm{V}_{0}-\mathrm{V}_{1250}\right) / \mathrm{V}_{0}$

299 The true density ( $\rho$ true) $(\mathrm{g} / \mathrm{ml})$ was determined using an AccuPyc 1330 helium pycnometer 300 (Micromeritics, Norcross, GA, USA). The equilibration rate was $0.0050 \mathrm{psig} / \mathrm{min}$ and the 301 number of purges 10 . The powder bed porosity $(\varepsilon)(\%)$ was calculated as described by 302 equation 7:

$$
\varepsilon=1-\frac{\rho_{b}}{\rho_{\text {true }}}(7)
$$

\section{$304 \quad$ 2.2.3.3. $\quad$ Ring shear tester}


305 The flowability of the powders was measured in triplicate with a ring shear tester (Type

306 RST-XS, Dietmar Schulze Schüttgutmesstechnik, Wolfenbüttel, Germany). In a first step,

307 the $30 \mathrm{~cm}^{3} \mathrm{XS}-\mathrm{Mr}$ shear cell was filled with powder and a normal load of $1000 \mathrm{~Pa}$ was

308 applied during the pre-shear step. For the actual measurements, the powder was sheared

309 under three different consolidation stresses $(400,600$ and $800 \mathrm{~Pa})$. The flowability of the

310 powders was evaluated via the flow function coefficient (ffc) (eq. 8), which was calculated

311 from the unconfined yield strength $\left(\sigma_{1}\right)(\mathrm{Pa})$ and major principal stress $(\mathrm{FC})(\mathrm{Pa})$. The bulk

312 density-weighed flow was expressed as ffp (eq. 9) and gives information about the flow

313 under gravity. $\rho_{w}$ is the density of water $(1 \mathrm{~g} / \mathrm{ml})$.

$$
f f c=\frac{\mathrm{FC}}{\sigma_{1}}
$$

$$
f f p=f f c \times \frac{\rho_{b}}{\rho_{w}}
$$

316 The wall friction angle (WFA) $\left(^{\circ}\right)$ was measured in triplicate using a XS-WL shear cell with

317 a 316 stainless steel bottom plate (surface roughness: $0.28 \mu \mathrm{m}$ ). After filling the cell with

$318 \pm 4 \mathrm{~mm}$ of powder, the wall friction was determined under decreasing wall normal stresses

319 (4000, 3280, 2560, 1840, 1120 and $400 \mathrm{~Pa})$. WFA was calculated from the resulting wall

320 yield locus.

\section{$321 \quad$ 2.2.3.4. FlowPro}

322 The flow rate $(\mathrm{FR})(\mathrm{mg} / \mathrm{s})$ through an orifice was measured $(\mathrm{n}=5)$ using the FlowPro ${ }^{\mathrm{TM}}$

323 (iPAT, Turku, Finland). The system consists of a sample holder with orifice and analytical

324 scale. The sample holder moves vertically and the upward motion breaks the powder arch

325 enabling the powder to flow freely through the orifice. The volume of the sample holder is 
$3265.96 \mathrm{ml}$ and the diameter of the orifice $3 \mathrm{~mm}$. The flow rate was calculated from the data

327 obtained by the analytical scale (Seppälä et al., 2010).

\section{2.2.3.5. FT4 powder rheometer}

329 Cylindrical vessels (diameter: $50 \mathrm{~mm}$ ) were used during material characterization with the

$330 \quad$ FT4 powder rheometer.

$331 \quad$ 2.2.3.5.1. Stability and variable flow rate

332 At the start of the stability and variable flow rate experiments, the vessel was filled with

$333160 \mathrm{ml}$ of sample. To ensure reproducible starting conditions, the sample was subjected

334 to a conditioning cycle before the start of each experiment. Flow energy (mJ) data was

335 collected from the energy generated by moving a blade through the powder from the top

336 of the vessel to the bottom (test cycle) with a blade tip speed of $100 \mathrm{~mm} / \mathrm{s}$. The test cycle

337 was repeated seven times to achieve stable flow energy (flow energy test $1-7$ ). The

338 sensitivity of the powder to shear rate was evaluated by gradually reducing the blade tip

339 speed $(100,70,40$ and $10 \mathrm{~mm} / \mathrm{s})$ during cycle $8-11$. The variables obtained from this

340 experiment are the basic flow energy (BFE) (mJ) (eq. 10), RSD on basic flow energy (RSD

341 BFE) (\%) (eq. 11), normalized BFE (nBFE) (mJ/g) (eq. 12), flow rate index (FRI) (eq. 13)

342 and specific energy (SE) $(\mathrm{mJ} / \mathrm{g})$ (eq. 14):

$$
B F E=\text { flow energy test } 7 \text { (10) }
$$

$$
n B F E=\frac{B F E}{\text { sample mass }}
$$




\subsection{Compressibility}

349 For the measurement of compressibility, the normal stress of a vented piston was

350 gradually increased $(0.5,1,2,4,6,8,10,12$ and $15 \mathrm{kPa})$ and the percentage of change

351 in volume was recorded. The compressibility at $15 \mathrm{kPa}$ was reported (C 15kPa) (\%).

\section{$352 \quad$ 2.2.3.5.3. Aeration}

353 A vessel with aeration base was filled with sample $(160 \mathrm{ml})$ and pre-conditioned to

354 standardize the state of the powder bed before each measurement. Initially, the flow

355 energy (AE 0) ( $\mathrm{mJ}$ ) was measured without aeration. Next, the air velocity (AV) was

356 gradually increased (AV: $0.5,1,2,4,6,8,10,15,20,30$ and $40 \mathrm{~mm} / \mathrm{s}$ ) while measuring

357 the corresponding flow energy (AE AV) (mJ). The reduction in flow energy caused by

358 transitioning from a densely stirred to a fluidized powder bed was quantified by normalizing

359 the aerated flow energies with the initial flow energy (AR AV) (eq. 15). Finally, the

360 maximum normalized aeration sensitivity (NAS) (s/mm) was calculated as the difference

361 in normalized flow energy divided by the difference in air velocity.

$$
A R A V=\frac{A E A V}{A E 0}
$$

\section{2.2.3.6. Charge density}

364 Triboelectric charging of the powders was measured using a GranuCharge (GranuTools,

365 Awans, Belgium). Powders were fed into the device using a vibratory feeder. Electrostatic 
366 charge was created during flow through a $316 \mathrm{~L}$ stainless steel $\mathrm{V}$-shaped tubing system

367 consisting of 2 separate tubes that form a $90^{\circ}$ angle. The tubes have a combined length

368 of $700 \mathrm{~mm}$ and an internal diameter of $47 \mathrm{~mm}$. At the end of the tubing system, samples

369 were collected inside a Faraday cup connected to an electrometer. Per test, $30 \mathrm{ml}$ of

370 powder was used and measurements were performed in triplicate. Charge density (CD)

$371(\mathrm{nC} / \mathrm{g})$ was calculated by dividing the net charge by the mass of the powder bed.

\section{2.2.4. Multivariate data analysis}

373 For each of the four determined feeding responses (FFmax, $F F_{\text {decay }}, \mathrm{RSD}$ and RE) a

374 separate PLS model was developed (table 2). The models were developed by regressing

375 the material property descriptors $(\mathrm{X})$ versus the feeding responses $(\mathrm{Y})$ of the powders

376 included in the calibration set (13 powders). In the models of the volumetric responses,

377 the applied screw speeds were also included in the $\mathrm{X}$ matrix since the volumetric feeding

378 responses $\left(\mathrm{FF}_{\max }\right.$ and $\left.\mathrm{FF}_{\text {decay }}\right)$ were determined at three screw speeds. Similarly, the feed

379 rate setpoint was added to the $\mathrm{X}$ matrix in the RSD and RE model as these gravimetric

380 feeding responses were measured at a low and high feed rate setpoint. Screw speed was

381 not included because the screw speed did not remain constant during the gravimetric

382 feeding experiments.

383 Prior to PLS regression, the data was pre-treated. First, the absolute value of charge

384 density was used in the PLS models, since charge density centered around zero and

385 varied in both the positive and negative direction. Without using the absolute value of

386 charge density, a powder with a very negative charge density value (i.e., highly charged)

387 would otherwise be categorized as a powder with a very low electrostatic charge (Van 
388 Snick et al., 2018a). Furthermore, the data was scaled to unit variance (UV) and mean-

389 centered prior to PLS regression. UV-scaling was performed by dividing each value by

390 the standard deviation of that variable and was necessary to normalize for the different

391 numerical ranges of the variables. For mean-centering, the mean of each variable was

392 subtracted from the data of that variable. Mean-centering results in a repositioning of the

393 coordinate system and makes the average point the origin, which improves the

394 interpretability of the model. Finally, a logarithmic transformation was applied on non-

395 normally distributed variables (dv50, ffc, ffp, BFE, RSD and RE) to approximate a normal

396 distribution (Eriksson et al., 2015).

397 The goodness of fit and predictive ability of the developed PLS models were assessed by 398 calculation of $R^{2}$ and $Q^{2}$, respectively. $Q^{2}$ values were obtained after performing a leave399 one-out cross-validation, in which sub-models were developed from a reduced calibration 400 dataset and the excluded data was predicted by the sub-models (Eriksson et al., 2015).

401 The number of PLS components providing the highest $\mathrm{Q}^{2}$ value was selected. The 402 predictive performance of the developed models was also assessed by predicting the 403 feeding responses of two external validation powders (S1500 and API 3). The relative 404 prediction error was calculated as the relative difference between the actual and predicted 405 feeding responses of the validation set.

406 Excluding some material property descriptors resulted in models with an improved 407 predictive performance. A first explanation for an improved predictive ability is that some 408 material property descriptors were highly correlated because they describe the same 409 material property (e.g., $\mathrm{HR}$ and $\mathrm{Cl}$ ). The problem of multiple descriptors representing one 410 material property, is that such a material property can artificially dominate the model due 
411 to a numerical overweight. Therefore, some of these highly correlated descriptors were

412 excluded, ensuring that the material properties had an equal weight in the model (Van

413 Snick et al., 2018a). Finally, material property descriptors that correlated poorly with the

414 feeding responses were excluded as these descriptors only introduce interfering variability

415 in the model. By selecting the material property descriptors with the highest correlation for

416 a specific feeding response, the predictive performance of the models was optimized

417 individually. An overview of the excluded material property descriptors for each model is

418 given in table 2. The PLS models were created using the SIMCA software (Version 15,

419 Umetrics, Umeå, Sweden).

\section{3. RESULTS AND DISCUSSION}

\section{3.1. Correlation between material properties and feeding behavior}

422 A four component PLS model was developed for $\mathrm{FF}_{\max }$ which explained 81.1 and $97.1 \%$

423 of the variation in the $X$ and $Y$ dataset, respectively (table 2). The loadings plot was used

424 to understand how the material property descriptors are related to each other and which

425 material property descriptors have an impact on the feeding responses (Eriksson et al.,

426 2015). In the PLS component (PLSC) 1 vs 2 loadings plot of the FFmax model (figure 4b),

$427 \mathrm{FF}_{\max }$, bulk and tapped density were located in the top right corner. This suggests a 428 positive correlation between $F F_{\max }$ and density, signifying that the numerical value of 429 FF $\max$, bulk and tapped density will change in the same way. Consequently, porosity $(\varepsilon)$ 430 was located at the opposite side of the origin (i.e., bottom left corner), meaning that $F F_{\max }$ 431 was negatively correlated with porosity. The positive correlation between density and $432 \mathrm{FF}_{\max }$ (i.e., negative correlation between porosity and $\mathrm{FF}_{\max }$ ) can be explained by the 
433 constant volume that is dispensed per screw revolution. For the same volume, a powder

434 with a high density will have a higher powder mass dispensed per screw revolution (i.e.,

435 feed factor) than a powder with a low density (Van Snick et al., 2017a). The scores plot

436 reveals how the powders are related to each other based on their material properties and

437 feeding behavior. The scores and loadings plots are complementary and superimposable,

438 meaning that materials with a specific location on the scores plot possess high values for

439 variables (i.e., material and feeding properties) with a similar location on the

440 corresponding loadings plot and low values for variables at the opposite side of the origin.

441 For the $\mathrm{FF}_{\max }$ model, it was observed that APAP D was located in the top right corner of

442 the PLSC 1 vs 2 scores plot (figure 4a). This is because APAP D possessed the highest

$443 \mathrm{FF}_{\max }$, bulk and tapped density of the investigated powders. AE 10 and $\mathrm{FF}_{\max }$ were also

444 positively correlated and was related to density as a dense powder requires more flow

445 energy to aerate its powder bed (figure 4b).

$446 \mathrm{FF}_{\max }$ was not only dependent on the density as $\mathrm{FF}_{\max } 30 \mathrm{rpm}$ of $\mathrm{CL}(0.244 \mathrm{~g} /$ revolution)

447 was clearly higher compared to PH105 (0.172 g/revolution), despite the similar bulk

448 density $( \pm 0.32 \mathrm{~g} / \mathrm{ml})$ of both powders. The flow descriptors (ffp and BFE) and FFmax had

449 similar PLSC 1 loadings, suggesting that powder flow and FFmax were positively correlated

450 (figure $4 b$ ). The better flow of $C L$ explains why the $F F_{\max }$ of CL was higher compared to

$451 \mathrm{PH} 105$ (ffp of 1.88 (CL) compared to 0.55 (PH105)). Free-flowing powders flow more

452 easily in the flight of the screws and therefore have a higher screw filling degree than

453 powders with a poor flowability. Overall, the density and powder flow were the material

454 properties with the largest impact on $\mathrm{FF}_{\max }$. Based on the loadings plot and the correlation

455 matrix (- 7\%) (not shown) it can be concluded that the screw speed (within the studied 
456 ranges of 10 and $90 \%$ of the maximum screw speed) was weakly anti-correlated with $457 \quad \mathrm{FF}_{\max }$.

458 In the feed factor profiles of the tested powders, FFmax was located at $100 \%$ hopper fill 459 level and the feed factor decreased when emptying the hopper (figure 2). At 100\% hopper 460 fill level, the powder mass in the hopper is at its maximum and the powder at the screw 461 inlet is compressed under the influence of the high powder mass in the hopper (i.e., 462 maximum density at the screw inlet). When the powder mass in the hopper decreases 463 during feeding, the powder is less compressed resulting in a reduction of the density at 464 the screw inlet and consequently the feed factor decreases. FF decay was used to describe 465 this decrease in feed factor and was defined as the \% hopper fill level where the feed 466 factor drops to $90 \%$ of $F F_{\max }$. A model with three components was developed for $F F_{\text {decay, }}$ 467 explaining 55.8 and $80.9 \%$ of the variation in the $X$ and $Y$ dataset, respectively (table 2).

$468 \mathrm{FF}_{\text {decay }}$ was positively correlated with the descriptors that describe the compressibility of 469 a powder bed (C 15kPa, HR and $\mathrm{Cl}$ ) (figure $5 \mathrm{~b}$ ). Powders with a high compressibility had 470 a high $\mathrm{FF}_{\text {decay, }}$ thus the decrease of feed factor already occurred at higher hopper fill 471 levels. For powders with a low compressibility, the compressive forces (i.e., powder mass 472 in the hopper) have a minimal impact on the density at the screw inlet resulting in an 473 almost unchanged feed factor during emptying of the hopper. The lowest FFdecay was 474 observed for powders with the lowest compressibility of the dataset (HD90 and DCP) 475 (figure 5a). However, the FF decay of 200M was lower than API SD (table 3), despite having 476 a similar compressibility (C $15 \mathrm{kPa}: \pm 22 \%)$. The reason for the lower FFdecay of $200 \mathrm{M}$ was 477 due to its better flow properties and higher density. Consequently, 200M can longer 478 maintain a constant feed factor because the powder flows more easily in the screw flights. 
479 The negative correlation of flow and density with FFdecay was confirmed by their opposite

480 location in the loadings plot (figure 5b). The loadings plot reveals that the screw speed

481 was weakly anti-correlated with $\mathrm{FF}_{\text {decay }}$ (figure $5 \mathrm{~b}$ ). According to the correlation matrix (not

482 shown), the magnitude of this correlation was low (-11\%) and was therefore considered

483 as irrelevant.

484 The model of the gravimetric feeding response RSD consisted of three PLSCs, which 485 explained 63.1 and $77.8 \%$ of the variation in the $X$ and $Y$ dataset, respectively (table 2).

486 From the PLSC 1 vs 2 loadings plot, it was observed that feed rate and RSD were clearly 487 negatively correlated, since they were located at opposite sides of the origin (figure 6b). 488 Consequently, a lower feed rate variability (RSD) will be observed when feeding at higher 489 throughputs. However, the value of SD was similar at low and high feed rates, but because 490 SD was divided by a higher mean feed rate for runs at a high feed rate, the calculated 491 RSD was lower compared to low feed rate runs (Ervasti et al., 2015). The correlation of 492 RSD with the material property descriptors was weaker as the highest correlation 493 observed in the correlation matrix (not shown) was only $40 \%$ (HR). From the loadings plot, 494 it can be concluded that the highest variability on the feed rate was observed for powders 495 with a low density, poor flow, high compressibility and small particle size, and that this 496 was primarily related to the ability to consistently fill the screws (figure 6b).

497 Two components were fitted in the RE model explaining 52.4 and $51.6 \%$ of the variation 498 in the $X$ and $Y$ dataset, respectively (table 2). From the PLSC 1 vs 2 loadings plot follows 499 that RE was positively correlated with porosity and negatively with both bulk and tapped 500 density (figure $7 \mathrm{~b}$ ). At the lowest feed rate setpoint of $0.1 \mathrm{~kg} / \mathrm{h}$, all powders could reach 501 the setpoint and the observed RE was close to zero. In contrast, powders with a low 
502 density were not capable of reaching the highest feed rate setpoint $(0.55 \mathrm{~kg} / \mathrm{h})$. For these

503 powders, the mean feed rate was much lower than $0.55 \mathrm{~kg} / \mathrm{h}$, resulting in a large RE. The

504 maximum feeding capacity of these powders was not high enough due to their low density.

505 This also explains why feed rate and RE were positively correlated because only for runs

506 at a high feed rate $(0.55 \mathrm{~kg} / \mathrm{h})$ a high RE was observed. The location of material properties

507 such as flowability and compressibility with respect to RE can also be explained by the

508 inability of low density powders to reach the highest feed rate setpoint as these powders

509 typically possess a poor flow and high compressibility. RE of most powders at both the

510 low and high feed rate setpoints, apart from the ones with a low density, was close to zero 511 (table 3).

\section{$512 \quad 3.2$. Predicting of the feeding responses}

513 The actual and predicted feeding responses (FF $F_{\max }, F F_{\text {decay }}, \mathrm{RSD}$ and $\left.\mathrm{RE}\right)$ of $\mathrm{S} 1500$ and

514 API 3 are displayed in table 4. The highest relative prediction error for the $\mathrm{FF}_{\max }$ was -

$5155.01 \%\left(F F_{\max } 6 \mathrm{rpm}\right.$ of $\left.\mathrm{S} 1500\right)$. For $\mathrm{FF}_{\text {decay, }}$ the highest relative prediction error was

516 observed for $\mathrm{FF}_{\text {decay }} 54 \mathrm{rpm}$ of $\mathrm{S} 1500$ (- $\left.25.07 \%\right)$. All other $\mathrm{FF}_{\text {decay }}$ values were predicted

517 with a relative prediction error lower than $10 \%$. For both validation powders, $\mathrm{FF}_{\max }$ was

518 predicted better than $\mathrm{FF}_{\text {decay }}$ and can be explained by the stronger correlation of $\mathrm{FF}_{\max }$

519 with the material properties. The strongest correlation between $\mathrm{FF}_{\max }$ and a material

520 property descriptor was $-91 \%(\varepsilon)$, whereas for $\mathrm{FF}_{\text {decay }}$ the strongest correlation was only $521-63 \%(f f p)$.

522 The highest relative prediction error for RSD was $-39.00 \%$ and was observed for the RSD

$5230.1 \mathrm{~kg} / \mathrm{h}$ of $\mathrm{S} 1500$, while the prediction error on the RSD $0.55 \mathrm{~kg} / \mathrm{h}$ of $\mathrm{S} 1500$ and API 3 
524 was -8.53 and $-0.62 \%$, respectively. The predictability of the RE model was low as the

$525 \mathrm{Q}^{2}$ value of this model was only 0.033 and the highest relative prediction error was

$5261895.97 \%(\mathrm{RE} 0.1 \mathrm{~kg} / \mathrm{h}$ of $\mathrm{S} 1500)$. However, the magnitude of the relative prediction error

527 should not be overestimated as the actual RE of this run was $0.01 \%$ and the predicted

$5280.20 \%$. More important for the RE model is that both the actual and predicted RE values

529 were close to zero for both validation powders, meaning that the model captured that the

530 density and maximum feeding capacity of these powders was high enough to reach the

531 investigated feed rate setpoints.

532 A reason for the low $Q^{2}$ value of the $R E$ model can be explained by the small numerical

533 variation in this gravimetric feeding response. Furthermore, the low $\mathrm{Q}^{2}$ value is an

534 indication of a weak relationship between the material properties and RE (Eriksson et al.,

535 2008), which is not desirable for an approach that aims to predict feeding behavior based

536 on material properties. However, the question is whether it is relevant to predict this

537 gravimetric feeding response, since a control system that is working properly will be able

538 to feed different powders at a feed rate close to the setpoint (i.e., low RE value).

539 Interestingly, since RE was close to zero and was similar for most powders, it can be

540 concluded that the feeder was capable of feeding the powders accurately at the low feed

541 rates tested in this study. The only powders for which a large RE value was observed,

542 were powders with a low density that could not reach the highest feed rate setpoint of 0.55

$543 \mathrm{~kg} / \mathrm{h}$, even when the control system selected the maximum screw speed. For these

544 powders, predicting RE is advantageous since it expresses the maximum feeding capacity

545 of that powder. However, the maximum feeding capacity was already captured by FFmax

546 and could be predicted with a very low prediction error. Therefore, when FFmax of a powder 
547 is known, predicting RE does not provide additional information regarding the maximum

548 feeding capacity of that powder.

549 Overall, the volumetric feeding responses $\left(\mathrm{FF}_{\max }\right.$ and $\left.\mathrm{FF}_{\text {decay }}\right)$ were predicted better than 550 the gravimetric feeding responses (RSD and RE). This is because the material properties

551 were more correlated with the volumetric feeding responses $\left(\mathrm{FF}_{\max }:-91 \%(\varepsilon)\right.$; $F F_{\text {decay: }}$ -

$55263 \%(f f p))$ than with the gravimetric feeding responses (RSD: 40\% (HR); RE: - 60\% (pb)).

553 In gravimetric mode, the control system tries to minimize the variability on the feed rate 554 and keeps the feed rate as close as possible to the setpoint, independently from the 555 powder that is being fed. This is in contrast with feeding in volumetric mode, where the 556 differences in feeding behavior are entirely related to the material properties since the 557 feed rate is not controlled. Finally, most feeding responses were predicted better for API 5583 compared to $\mathrm{S} 1500$. A two component PCA model ( $R^{2} \mathrm{X}: 0.617$ and $\left.\mathrm{Q}^{2}: 0.313\right)$ was 559 constructed, including all material property descriptors and all powders (both calibration 560 and validation powders). This allowed to investigate how the validation powders were 561 related to the calibration powders based on their material properties. The scores plot of 562 this PCA model reveals that more calibration powders were situated in the same region 563 as API 3 than in the region of $\mathrm{S} 1500$ (figure 8), meaning that the calibration set contained 564 more powders with similar material properties as API 3. This emphasizes that the size of 565 the calibration set is critical for this multivariate approach to be successful. Therefore, 566 models should be updated when material properties and feeding responses of new 567 powders are obtained (Wang et al., 2017). This will further improve the predictability of 568 the models as the probability will increase that the material properties and feeding 569 responses of a new powder are closely related to a powder in the calibration set. 


\section{CONCLUSIONS}

572 In this study, multivariate models (PLS) were developed that allow to predict the volumetric

573 and gravimetric feeding behavior of a low feed rate feeder based on material properties.

574 The maximum feed factor $\left(F F_{\max }\right)$ and decay in feed factor (FF

575 during volumetric feeding experiments. From gravimetric feeding experiments, the

576 variability on the feed rate (RSD) and the difference between the mean feed rate and

577 setpoint (RE) were obtained. Overall, the volumetric feeding responses (FF $F_{\max }$ and

578 FF $\left.F_{\text {decay }}\right)$ were predicted with the highest accuracy as they correlated better with the

579 material properties than the gravimetric responses. This is because in gravimetric mode,

580 the feed rate is controlled by the control system, which reduces the impact of material

581 properties on the feeding behavior. For RE, almost no variation was observed between

582 the different powders. Only for low density powders, where the highest gravimetric feed

583 rate setpoint could not be reached, RE was a measure of the maximum feeding capacity.

584 However, the maximum feeding capacity was already obtained from FFmax. Therefore,

585 developing a model that correlates material properties with RE might be unnecessary.

586 Finally, API 3 was predicted better than S1500 since the calibration set contained more

587 powders with similar material properties as API 3. Hence, updating the models with new

588 powders is important to further improve the predictive performance. The used multivariate

589 models assume linear relationships between the variables. However these relationships

590 do not always tend to be linear. Therefore, one of the future perspectives is to investigate

591 modelling approaches that can handle non-linearity in the data with the aim of further

592 improving the predictive performance of the developed models. The approach applied in 
593 this study will allow to reduce the number of feeding experiments during process

594 development, leading to a more efficient and faster development of new drug products.

\section{FUNDING}

596 Research funded by a PhD fellowship SB (1S $18916 \mathrm{~N})$ of the Research Foundation

597 Flanders (FWO). 


\section{REFERENCES}

Besenhard, M.O., Karkala, S.K., Faulhammer, E., Fathollahi, S., Ramachandran, R., Khinast, J.G., 2016. Continuous feeding of low-dose APIs via periodic micro dosing. Int. J. Pharm. 509, 123-134. https://doi.org/10.1016/j.ijpharm.2016.05.033

Blackshields, C., Crean, A., 2017. Continuous powder feeding for pharmaceutical solid dosage form manufacture: a short review. Pharm. Dev. Technol. 1-7.

Bostijn, N., Renterghem, J. Van, Dhondt, W., Vervaet, C., Beer, T. De, 2018. A continuous manufacturing concept for a pharmaceutical oral suspension. Eur. J. Pharm. Sci. 123, 576-583. https://doi.org/10.1016/j.ejps.2018.08.015

Boukouvala, F., lerapetritou, M.G., 2013. Surrogate-Based Optimization of Expensive Flowsheet Modeling for Continuous Pharmaceutical Manufacturing. J Pharm Innov 8, 131-145. https://doi.org/10.1007/s12247-013-9154-1

Clayton, J., 2015. Identifying Powder Properties that Define Process Performance. Pharm. Technol. 38, 72-76.

Coperion K-Tron, 2012. Smart Feeding Solutions for Bulk Material Processing.

El Hagrasy, A.S., Hennenkamp, J.R., Burke, M.D., Cartwright, J.J., Litster, J.D., 2013. Twin screw wet granulation: Influence of formulation parameters on granule properties and growth behavior. Powder Technol. 238, 108-115. https://doi.org/10.1016/j.powtec.2012.04.035

Engisch, W.E., Muzzio, F.J., 2015a. Loss-in-Weight Feeding Trials Case Study: Pharmaceutical Formulation. J Pharm Innov 10, 56-75. https://doi.org/10.1007/s12247-014-9206-1

Engisch, W.E., Muzzio, F.J., 2015b. Feedrate deviations caused by hopper refill of loss-in-weight feeders. Powder Technol. 283, 389-400. https://doi.org/10.1016/j.powtec.2015.06.001

Engisch, W.E., Muzzio, F.J., 2012. Method for characterization of loss-in-weight feeder equipment. Powder Technol. 228, 395-403. https://doi.org/10.1016/j.powtec.2012.05.058

Eriksson, L., Johansson, E., Kettaneh-Wold, N., Trygg, J., Wikstrom, C., Wold, S., 2015. Multi- and Megavariate Data Analysis Part 1.

Eriksson, L., Johansson, E., Kettaneh-Wold, N., Wikstrom, C., Wold, S., 2008. Design of Experiments.

Ervasti, T., Simonaho, S., Ketolainen, J., Forsberg, P., Fransson, M., Wikström, H., Folestad, S., Lakio, S., Tajarobi, P., 2015. Continuous manufacturing of extended release tablets via powder mixing and direct compression. Int. J. Pharm. 495, 290-301. https://doi.org/10.1016/j.ijpharm.2015.08.077

Fonteyne, M., Correia, A., De Plecker, S., Vercruysse, J., Ili, I., Zhou, Q., Vervaet, C., Remon, J.P., Onofre, F., Bulone, V., De Beer, T., 2015. Impact of microcrystalline cellulose material attributes: A case study on continuous twin screw granulation. Int. J. Pharm. 478, 705-717. https://doi.org/10.1016/j.ijpharm.2014.11.070

Fonteyne, M., Wickström, H., Ketolainen, J., Sandler, N., Rantanen, J., Naelapaa, K., T, D.B., Peeters, E., Vercruysse, J., Ehlers, H., Vervaet, C., 2014. Influence of raw material properties upon critical quality attributes of continuously produced granules and tablets. Eur. J. Pharm. Biopharm. 87, 252-263. https://doi.org/10.1016/j.ejpb.2014.02.011

Garcia-Munoz, S., 2014. Two novel methods to analyze the combined effect of multiple raw-materials and processing conditions on the product's final attributes: JRPLS and TPLS. Chemom. Intell. Lab. Syst. 133, 49-62. https://doi.org/10.1016/j.chemolab.2014.02.006

Haware, R. V., Tho, I., Bauer-Brandl, A., 2009a. Multivariate analysis of relationships between material properties, process parameters and tablet tensile strength for $\alpha$-lactose monohydrates. Eur. J. Pharm. Biopharm. 73, 424-431. https://doi.org/10.1016/j.ejpb.2009.08.005

Haware, R. V., Tho, I., Bauer-Brandl, A., 2009b. Application of multivariate methods to compression behavior evaluation of directly compressible materials. Eur. J. Pharm. Biopharm. 72, 148-155. https://doi.org/10.1016/j.ejpb.2008.11.008

Herting, M.G., Kleinebudde, P., 2007. Roll compaction/dry granulation: Effect of raw material particle size on granule and tablet properties. Int. J. Pharm. 338, 110-118. https://doi.org/10.1016/j.ijpharm.2007.01.035

Nowak, S., 2016. Three ways to improve continuous loss-in-weight feeding accuracy. Powder Bulk Eng.

Seppälä, K., Heinämäki, J., Hatara, J., Seppälä, L., Yliruusi, J., 2010. Development of a New Method to Get a Reliable Powder Flow Characteristics Using Only 1 to $2 \mathrm{~g}$ of Powder. AAPS PharmSciTech 11, 402-408. https://doi.org/10.1208/s12249-010-9397-9

Simonaho, S.P., Ketolainen, J., Ervasti, T., Toiviainen, M., Korhonen, O., 2016. Continuous manufacturing of tablets with PROMIS-line Introduction and case studies from continuous feeding, blending and tableting. Eur. J. Pharm. Sci. 90, 38-46. https://doi.org/10.1016/j.ejps.2016.02.006

Thoorens, G., Krier, F., Rozet, E., Carlin, B., Evrard, B., 2015. Understanding the impact of microcrystalline cellulose physicochemical properties on tabletability. Int. J. Pharm. 490, 47-54. https://doi.org/10.1016/j.ijpharm.2015.05.026

Van Snick, B., Dhondt, J., Pandelaere, K., Bertels, J., Mertens, R., Klingeleers, D., Di Pretoro, G., Remon, J.P., Vervaet, C., De Beer, T., Vanhoorne, V., 2018a. A multivariate raw material property database to facilitate drug product development and enable in-silico design of pharmaceutical dry powder processes. Int. J. Pharm. 549, 415-435. https://doi.org/10.1016/j.jjpharm.2018.08.014

Van Snick, B., Grymonpré, W., Dhondt, J., Pandelaere, K., Di Pretoro, G., Remon, J.P., De Beer, T., Vervaet, C., Vanhoorne, V., 2018b. Impact of blend properties on die filling during tableting. Int. J. Pharm. 549, 476-488. https://doi.org/10.1016/j.ijpharm.2018.08.015

Van Snick, B., Holman, J., Cunningham, C., Kumar, A., Vercruysse, J., Beer, T. De, Remon, J.P., Vervaet, C., 2017a. Continuous direct compression as manufacturing platform for sustained release tablets. Int. J. Pharm. 519, 390-407. https://doi.org/10.1016/j.ijpharm.2017.01.010

Van Snick, B., Pandelaere, K., Vanhoorne, V., Dhondt, J., Tambwekar, K., De Beer, T., Remon, J.P., Vervaet, C., 2017b. EVALUATION OF FEEDING IN A CONTINUOUS MANUFACTURING PLATFORM.

Wang, Y., Li, T., Muzzio, F.J., Glasser, B.J., 2017. Predicting feeder performance based on material flow properties. Powder Technol. 308, 135148. https://doi.org/10.1016/j.powtec.2016.12.010

Willecke, N., Szepes, A., Wunderlich, M., Remon, J.P., Vervaet, C., Beer, T. De, 2017. Identifying overarching excipient properties towards an indepth understanding of process and product performance for continuous twin-screw wet granulation. Int. J. Pharm. 522, $234-247$. https://doi.org/10.1016/j.ijpharm.2017.02.028 


\begin{tabular}{|c|c|c|}
\hline $\begin{array}{c}\text { Characterization } \\
\text { technique }\end{array}$ & Material property descriptor & Abbreviation \\
\hline Laser diffraction & $50 \%$ cumulative undersize of the volumetric distribution & dv50 \\
\hline $\begin{array}{l}\text { Tapping device } \\
\text { and pycnometer }\end{array}$ & $\begin{array}{l}\text { Bulk density } \\
\text { Tapped density } \\
\text { Hausner ratio } \\
\text { Carr index } \\
\text { True density } \\
\text { Porosity }\end{array}$ & $\begin{array}{c}\rho b \\
\rho t \\
\mathrm{HR} \\
\mathrm{Cl} \\
\rho \text { true } \\
\varepsilon\end{array}$ \\
\hline Ring shear tester & $\begin{array}{l}\text { Flow function coefficient } \\
\text { Unconfined yield strength } \\
\text { Major principal stress } \\
\text { Bulk density-weighed flow } \\
\text { Wall friction angle }\end{array}$ & $\begin{array}{l}\mathrm{ffc} \\
\sigma_{1} \\
\text { FC } \\
\text { ffp } \\
\text { WFA }\end{array}$ \\
\hline FlowPro & Flow rate & FR \\
\hline $\begin{array}{l}\text { FT4 powder } \\
\text { rheometer }\end{array}$ & $\begin{array}{c}\text { Basic flow energy } \\
\text { RSD on basic flow energy } \\
\text { Normalized basic flow energy } \\
\text { Flow rate index } \\
\text { Specific energy } \\
\text { Compressibility at } 15 \mathrm{kPa} \\
\text { Flowability energy at air velocity of } 10 \text { and } 40 \mathrm{~mm} / \mathrm{s} \\
\text { Normalized flowability energy at air velocity of } 10 \text { and } 40 \mathrm{~mm} / \mathrm{s} \\
\text { Normalized aeration sensitivity }\end{array}$ & $\begin{array}{l}\text { BFE } \\
\text { RSD BFE } \\
\text { nBFE } \\
\text { FRI } \\
\text { SE } \\
\text { C } 15 \mathrm{kPa} \\
\text { AE } 10 \text { and AE } 40 \\
\text { AR } 10 \text { and AR } 40 \\
\text { NAS }\end{array}$ \\
\hline GranuCharge & Charge density & $C D$ \\
\hline
\end{tabular}

Table 1. Overview of the characterization techniques, corresponding material property descriptors and abbreviations. 


\begin{tabular}{|c|c|c|c|c|}
\hline & $F F_{\max }$ & $\mathrm{FF}_{\text {decay }}$ & RSD & $\mathrm{RE}$ \\
\hline $\begin{array}{l}\text { Excluded } \\
\text { material } \\
\text { property } \\
\text { descriptors }\end{array}$ & $\begin{array}{c}\mathrm{HR}, \sigma_{1}, \mathrm{FC}, \mathrm{RSD} \\
\mathrm{BFE}, \mathrm{FRI}, \mathrm{SE}, \mathrm{AR} \\
10 \text { and CD }\end{array}$ & Ptrue and FC & $\mathrm{Cl}, \mathrm{FRI}$ and NAS & $\mathrm{HR}$ \\
\hline$R^{2} X$ & 0.811 & 0.558 & 0.631 & 0.524 \\
\hline$R^{2} Y$ & 0.971 & 0.809 & 0.778 & 0.516 \\
\hline $\mathrm{Q}^{2}$ & 0.946 & 0.585 & 0.344 & 0.033 \\
\hline $\begin{array}{l}\text { \# of PLS } \\
\text { components }\end{array}$ & 4 & 3 & 3 & 2 \\
\hline
\end{tabular}

Table 2. Overview of the developed PLS models. 


\begin{tabular}{|c|c|c|c|c|c|c|c|c|c|c|}
\hline Material & $\begin{array}{l}F_{\text {max }} \\
6 \text { rpm } \\
\text { (g/revo } \\
\text { lution) }\end{array}$ & $\begin{array}{l}F_{\text {max }} \\
30 \text { rpm } \\
\text { (g/revo } \\
\text { lution) }\end{array}$ & $\begin{array}{l}F_{\text {max }} \\
54 \text { rpm } \\
\text { (g/revol } \\
\text { ution) }\end{array}$ & $\begin{array}{c}\mathrm{FF}_{\text {decay }} \\
6 \mathrm{rpm} \\
(\%)\end{array}$ & $\begin{array}{c}F_{\text {decay }} \\
30 \text { rpm } \\
(\%)\end{array}$ & $\begin{array}{c}\mathrm{FF}_{\text {decay }} \\
54 \mathrm{rpm} \\
(\%)\end{array}$ & $\begin{array}{c}\text { RSD } \\
0.1 \mathrm{~kg} / \mathrm{h} \\
(\%)\end{array}$ & $\begin{array}{c}\text { RSD } \\
0.55 \mathrm{~kg} / \mathrm{h} \\
(\%)\end{array}$ & $\begin{array}{c}\text { RE } 0.1 \\
\text { kg/h } \\
(\%)\end{array}$ & $\begin{array}{l}\text { RE } 0.55 \\
\mathrm{~kg} / \mathrm{h}(\%)\end{array}$ \\
\hline$P M$ & 0.141 & 0.082 & 0.075 & 86.8 & 93.7 & 68.3 & 59.5 & 27.3 & 0.5 & 46.2 \\
\hline P P & 0.302 & 0.287 & 0.267 & 66.0 & 70.2 & 69.0 & 87.3 & 17.2 & 1.9 & 0.3 \\
\hline$P D$ & 0.712 & 0.703 & 0.684 & 53.5 & 58.7 & 52.1 & 76.0 & 12.3 & 0.3 & 0.0 \\
\hline API SD & 0.148 & 0.092 & 0.109 & 97.4 & 69.8 & 92.1 & 220.0 & 52.0 & 1.0 & 43.2 \\
\hline $200 M$ & 0.484 & 0.473 & 0.452 & 36.0 & 41.3 & 43.9 & 60.1 & 6.1 & 0.3 & 0.4 \\
\hline PH105 & 0.175 & 0.172 & 0.164 & 41.4 & 38.5 & 29.8 & 29.0 & 7.9 & 0.1 & 0.6 \\
\hline DCP & 0.384 & 0.400 & 0.402 & 15.5 & 14.3 & 18.0 & 73.6 & 12.4 & 1.6 & 0.0 \\
\hline HD90 & 0.263 & 0.253 & 0.251 & 18.3 & 15.4 & 6.8 & 57.7 & 14.3 & 1.9 & 1.1 \\
\hline $\mathrm{CL}$ & 0.188 & 0.244 & 0.175 & 61.2 & 73.3 & 85.8 & 72.0 & 12.3 & 0.9 & 0.8 \\
\hline MgSt & 0.140 & 0.124 & 0.116 & 65.2 & 91.1 & 88.5 & 106.7 & 38.4 & 4.1 & 30.2 \\
\hline API 1 & 0.042 & 0.045 & 0.048 & 84.2 & 77.6 & 79.4 & 191.8 & 115.5 & 3.1 & 64.4 \\
\hline API 2 & 0.205 & 0.108 & 0.089 & 71.9 & 47.4 & 35.1 & 140.6 & 28.1 & 1.2 & 14.0 \\
\hline API M & 0.054 & 0.027 & 0.026 & 85.7 & 43.1 & 21.5 & 52.2 & 69.0 & 0.2 & 76.7 \\
\hline API 3 & 0.226 & 0.209 & 0.191 & 65.2 & 62.6 & 58.9 & 124.3 & 25.7 & 1.9 & 0.7 \\
\hline S1500 & 0.470 & 0.426 & 0.424 & 33.7 & 32.8 & 35.7 & 79.5 & 13.2 & 0.0 & 0.5 \\
\hline
\end{tabular}

Table 3. Feeding responses of the tested powders. 


\begin{tabular}{|c|c|c|c|c|c|c|}
\hline & \multicolumn{3}{|c|}{$S 1500$} & \multicolumn{3}{|c|}{ API 3} \\
\hline & Actual & Predicted & $\begin{array}{c}\text { Relative } \\
\text { prediction error } \\
(\%)\end{array}$ & Actual & Predicted & $\begin{array}{c}\text { Relative } \\
\text { prediction error } \\
(\%)\end{array}$ \\
\hline $\mathrm{FF}_{\max } 6 \mathrm{rpm}$ (g/revolution) & 0.470 & 0.447 & -5.01 & 0.226 & 0.224 & -0.88 \\
\hline $\mathrm{FF}_{\max } 30 \mathrm{rpm}$ (g/revolution) & 0.426 & 0.429 & 0.61 & 0.209 & 0.207 & -0.94 \\
\hline $\mathrm{FF}_{\max } 54 \mathrm{rpm}$ (g/revolution) & 0.424 & 0.411 & -3.05 & 0.191 & 0.189 & -1.01 \\
\hline $\mathrm{FF}_{\text {decay }} 6 \mathrm{rpm}(\%)$ & 33.7 & 34.3 & 1.87 & 65.2 & 65.2 & 0.00 \\
\hline $\mathrm{FF}_{\text {decay }} 30$ rpm (\%) & 32.7 & 30.5 & -6.81 & 62.6 & 61.4 & -1.88 \\
\hline FF decay 54 rpm (\%) & 35.7 & 26.7 & -25.07 & 58.9 & 57.7 & -2.11 \\
\hline RSD 0.1 kg/h (\%) & 79.5 & 48.5 & -39.00 & 124.3 & 102.7 & -17.41 \\
\hline RSD 0.55 kg/h (\%) & 13.2 & 12.1 & -8.53 & 25.7 & 25.5 & -0.62 \\
\hline RE 0.1 kg/h (\%) & 0.01 & 0.20 & 1895.97 & 1.94 & 0.78 & -60.07 \\
\hline RE $0.55 \mathrm{~kg} / \mathrm{h}(\%)$ & 0.45 & 0.36 & -19.34 & 0.70 & 1.41 & 101.25 \\
\hline
\end{tabular}

Table 4. Overview of the actual and predicted feeding responses of the validation powders. 
Figure 1. Overview of the experimental setup: K-Tron MT12 twin screw LIW feeder (left) and catch scale (right).

Figure 2. Feed factor profile of lactose monohydrate (200M) at a screw speed of 6,30 and $54 \mathrm{rpm}$ used to determine the volumetric feeding responses: maximum feed factor ( $\left.F F_{\max }\right)$ and feed factor decay (FFdecay).

Figure 3. Gravimetric feeding data of lactose monohydrate $(200 \mathrm{M})$ at $0.55 \mathrm{~kg} / \mathrm{h}$ used to determine the gravimetric feeding response: standard deviation (SD).

Figure 4. PLSC 1 vs 2 scores (a) and loadings (b) plot of the FFmax model. The abbreviations of the powders in the scores plot and of the descriptors in the loadings plot are described in the materials and methods section. Only the runs performed at a screw speed of $30 \mathrm{rpm}$ are displayed in the scores plot since the runs at the three screw speeds largely overlap in the scores plot (not shown).

Figure 5. PLSC 1 vs 2 scores (a) and loadings (b) plot of the FFdecay model. The abbreviations of the powders in the scores plot and of the descriptors in the loadings plot are described in the materials and methods section. Only the runs performed at a screw speed of $30 \mathrm{rpm}$ are displayed in the scores plot since the runs at the three screw speeds largely overlap in the scores plot (not shown).

Figure 6. PLSC 1 vs 2 scores (a) and loadings (b) plot of the RSD model. The abbreviations of the powders in the scores plot and of the descriptors in the loadings plot are described in the materials and methods section. The runs performed at the low $(L)$ and high $(\mathrm{H})$ feed rate setpoint $(0.1$ and $0.55 \mathrm{~kg} / \mathrm{h})$ are displayed in the scores plot. 
Figure 7. PLSC 1 vs 2 scores (a) and loadings (b) plot of the RE model. The abbreviations of the powders in the scores plot and of the descriptors in the loadings plot are described in the materials and methods section. The runs performed at the low $(\mathrm{L})$ and high $(\mathrm{H})$ feed rate setpoint $(0.1$ and $0.55 \mathrm{~kg} / \mathrm{h})$ are displayed in the scores plot.

Figure 8. Scores plot of the PCA model constructed of the material properties of all investigated powders. The abbreviations of the powders in the scores plot are described in the materials section. 